\title{
Practical experiences with granular activated carbon (GAC) at the Rietvlei Water Treatment Plant
}

\author{
Michele Clements and Johannes Haarhoff \\ Water Research Group, Rand Afrikaans University, PO Box 524, Auckland Park 2006, South Africa
}

\begin{abstract}
The Rietvlei Water Treatment Plant was extended with a granular activated carbon (GAC) filtration system after an exhaustive series of tests, which were started in 1994. Upon commissioning towards the middle of 1999, a year of close monitoring followed to measure the GAC performance at full-scale. After verification that the GAC does indeed ensure a high quality product under all conditions, the emphasis shifted to the optimisation of the GAC handling and regeneration system. Frequently moving the entire GAC inventory from the filters to an off-site regeneration plant and back requires significant operational effort and contributes a major part of the total cost of the GAC system. A number of systematic investigations were carried out in response to a number of practical questions that arose at Rietvlei. The first part of the study was directed towards tracking and quantifying the GAC on and off site. The main findings were that $10.0 \%$ of the GAC is lost from the filter during backwashing $(0.3 \%)$ and removal of GAC from the filter for regeneration $(9.7 \%)$. The sump does not trap all this GAC and $2.3 \%$ of the total inventory is lost to the river. Inserting a sieve at the outlet of the sump can eliminate this loss. A further $80.3 \%$ of the GAC in a filter is removed for regeneration, of which $18.7 \%$ is lost during the regeneration process. The minimising of this loss can only be achieved through the optimisation of the regeneration process, which falls within the domain of the regeneration contractor. The second part of the study was directed at the behaviour of the GAC whilst within the filter bed. The porosity and sphericity were determined by laboratory tests and calculations. The porosity was found to be 0.69 for the $12 \times 40$ size carbon and 0.66 for the $8 \times 30$ size carbon. By using a calibrated bed expansion model, bed expansion could be calculated at $9^{\circ} \mathrm{C}$ and $23^{\circ} \mathrm{C}$ for the two carbon gradings; the maximum temperature range experienced at Rietvlei. The main finding of this part of the study was that the average available freeboard is $650 \mathrm{~mm}$ for the $12 \times 40$ grading and $430 \mathrm{~mm}$ for the $8 \times 30$ grading, and therefore no GAC should wash over the weir at all during backwashing. The third part of the study measured the physical changes of the GAC found at different points in the GAC cycle. The main findings were that the small fraction of GAC washed out of the bed during backwashing and removal has a finer grading, higher apparent density and lower adsorption capacity than the GAC in the filter bed. There seems to be no marked attrition of the carbon or generation of fines during the removal and transport of the GAC to the regeneration plant. After regeneration, there was a $7.0 \%$ decrease in apparent density and a $30.0 \%$ increase in adsorption capacity. The final part of the study correlated the adsorption capacity of the GAC with its time in use as well as UV254 removal. After regeneration, UV254 removal begins at approximately $20.0 \%$ and declines to $14.0 \%$ after $400 \mathrm{~d}$ of operation, and to $10.0 \%$ after $600 \mathrm{~d}$. After regeneration, the iodine number begins at approximately $800 \mathrm{~g} / \mathrm{mg}$, declines to $600 \mathrm{~g} / \mathrm{mg}$ after $400 \mathrm{~d}$ of operation, and to $500 \mathrm{~g} / \mathrm{mg}$ after $600 \mathrm{~d}$.
\end{abstract}

Keywords: granular activated carbon, regeneration, bed expansion, backwashing, abrasion, apparent density

\section{Introduction}

Rietvlei Dam, situated on the Hennops River, has been supplying the city of Pretoria with drinking water since 1934. Through the years the population around the Hennops River has grown, and the quality of the water in the dam has deteriorated. For this reason the water treatment plant was upgraded in 1988 , which improved the performance of the plant for some years. Because of extensive agricultural activities in the catchment area, increasing concentrations of nitrogen and phosphorus flowed into the dam, which increased the growth of algae.

Van Staden (1996) did a pilot-plant study for $192 \mathrm{~d}$ on different auxiliary treatment possibilities at Rietvlei. Granular activated carbon (GAC) and ozone possibilities were investigated. His results indicated that an auxiliary GAC plant would be the optimum choice when considering the economics and quality of the water. To eliminate the taste and odour caused by the algae, the GAC plant

* To whom all correspondence should be addressed.

ㄲㅛㅛ +2711 489 2354; fax: +2711 489 2148; e-mail: mcl@ing.rau.ac.za Received 29 October 2002; accepted in revised form 11 November 2003. was built and commissioned on 22 November 1999. Upon commissioning, a year of close monitoring by De Kloe (2000) followed to measure the GAC performance at full-scale. After verification that the GAC does indeed ensure a high quality product under all conditions, the emphasis shifted to the optimisation of the GAC handling and regeneration system.

The initial indications were that the GAC losses are higher than originally expected, and that most of these losses occurred during the regeneration cycle. If these losses could be reduced, and the GAC regenerated less frequently, the operational costs could be sharply reduced. As the GAC plant at Rietvlei is the only working plant of its kind in South Africa, there is an absence of local data on the expected losses during plant operations, handling and regeneration of the GAC. This paper therefore addresses a number of systematic investigations carried out in response to the following practical questions that arose at Rietvlei:

- How large are the GAC losses? Can these losses be identified and quantified?

- How does the GAC behave in situ in the filter beds?

- How is the GAC changed during the regeneration cycle? 


\section{GAC losses and pathways}

The Rietvlei GAC management system is best modelled as two parallel circuits:

- The first off-site circuit removes GAC from the filters, transports it in bags by truck to a commercial regeneration plant where a fraction of GAC is lost due to the regeneration process. The remaining regenerated GAC is brought back onto the site and loaded into the filters.

- The second on-site circuit originates from the GAC washed from the filter beds during normal operation. This GAC from the filters is collected in a sump, which retains a fraction of the GAC whilst the rest of the GAC is washed into a river with the supernatant from the sump. The sump is periodically excavated, the GAC placed in bags, sent to the off-site regeneration plant and returned to the filters after regeneration. After a filter is filled with regenerated GAC, it is topped up to its original level from a stockpile of new GAC kept in reserve.

During normal operation, the only GAC lost from the filters, is the GAC swept out with the backwash water to the sump. When the GAC is removed from the filter for regeneration, it is kept in suspension by the backwash system and sucked out as slurry with a venturi system. During this process, a further volume of GAC is washed out to the sump. It should be further noted that a small volume of GAC remains in the filter after removal to act as a protective layer above the filter nozzles. The losses can therefore be presented as follows:

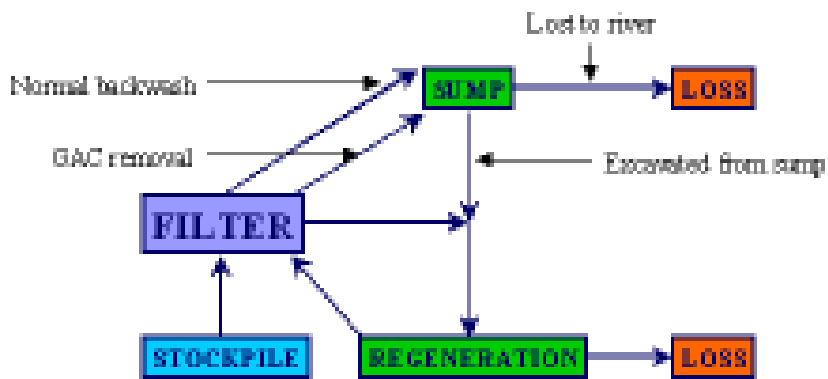

Figure 1

Representation of the losses in the Rietvlei GAC management system

There are a number of measuring points in the system:

- The level in each filter is carefully measured whenever GAC is placed in the filter, and again before the GAC is removed for regeneration.

- As the GAC is transferred to the bags on site, the number of transfer bins (with a known volume) is noted.

- As the GAC arrives at the regeneration plant, the volume is again measured by counting the number of volumetric bins filled.

- After regeneration, the GAC is again volumetrically measured in the same manner as before.

- On site, the volume of excavated GAC from the sump is also determined from the number of bags filled.

\section{Mathematical representation of the system}

The physical system can be diagrammatised and mathematically represented as shown in Fig. 2. The basis of the mathematical

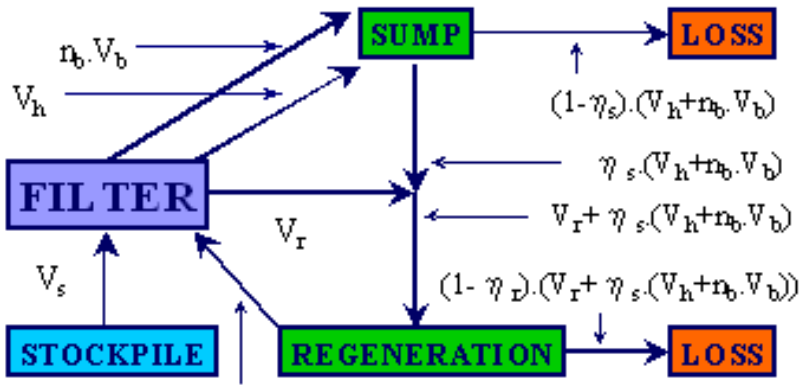

$$
\eta_{\mathrm{r}} \cdot\left(\mathrm{V}_{\mathrm{r}}+\eta_{\mathrm{s}} \cdot\left(\mathrm{V}_{\mathrm{h}}+\eta_{\mathrm{b}} \cdot \mathrm{V}_{\mathrm{b}}\right)\right)
$$

Figure 2

Mathematical representation of the Rietvlei GAC management system

model is to consider the GAC flow for a single filter during a full regeneration cycle, i.e. from the point where the filter is filled with new or regenerated GAC, back to where it is again returned to the same condition after the GAC has been exhausted, regenerated and topped up again. The symbols and units are:

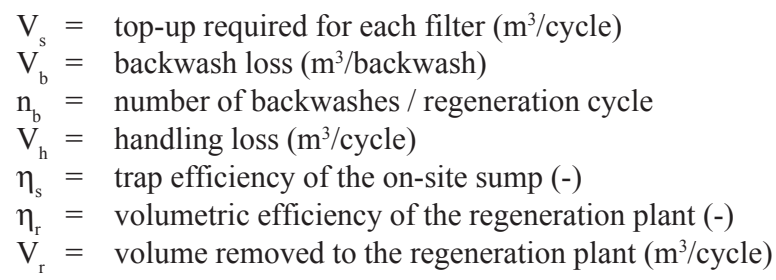

\section{Calibrating the model}

The above model contains seven unknowns. Once these unknowns are quantified, the flow of GAC through the system can be uniquely defined. The rest of this section describes the direct and indirect measures used to calibrate the model based on the first 23 months of operational experience.

\section{Number of backwashes/cycle $n_{b}$}

The events between the first and the second excavation of GAC from the sump were carefully reconstructed from the plant records. During this time, 1024 filter backwashes were recorded and the GAC of 5 filters removed. The number of backwashes/cycle was thus $\mathrm{n}_{\mathrm{b}}=1024 / 5=205$.

\section{Backwash loss $\mathbf{V}_{\mathrm{b}}$}

The volume of GAC washed out from a filter during a single typical backwash was directly measured by inserting a sieve in the backwash channel immediately downstream of the filter. In this way, the backwashing loss rate was found to be $V_{b}=0.00025 \mathrm{~m}^{3} /$ backwash.

\section{Top-up for each filter $\mathbf{V}_{\mathrm{s}}$}

The total GAC volume, when all 20 filters are topped up to their maximum level, is $308 \mathrm{~m}^{3}$ or $15.4 \mathrm{~m}^{3} /$ filter. When the plant was commissioned, a reserve volume of GAC was stored on site to be used to top up each filter after its regenerated GAC had been returned to the filter. After the GAC of 25 filters had been regenerated, a total volume of $81 \mathrm{~m}^{3}$ had been used for top-up to replace GAC lost due to handling and regeneration. Thus the topup volume required was $\mathrm{V}_{\mathrm{s}}=81 / 25=3.24 \mathrm{~m}^{3} /$ cycle. 


\section{Volume removed $\mathrm{V}_{\mathrm{r}}$}

There are two methods available to estimate the total volume of GAC removed. In the first the level of GAC in the filter is measured before and after the GAC is removed from the filter for regeneration. The total volume removed is then estimated. The average volume thus calculated for the first 25 filters regenerated, indicated that an average volume of $12.68 \mathrm{~m}^{3}$ of GAC had been removed from each filter. In the second method, when the GAC arrived at the regeneration plant, it was again volumetrically measured by counting the number of $1 \mathrm{~m}^{3}$ bins filled. This was done for 19 filters, and the average volume of GAC removed per filter was $12.03 \mathrm{~m}^{3}$. These two independent estimates are remarkably close, with an average of $\mathrm{V}_{\mathrm{r}}=12.36 \mathrm{~m}^{3} /$ cycle.

\section{Regeneration efficiency $\eta_{r}$}

The GAC is volumetrically measured upon arrival at the regeneration plant, and again after regeneration. The same regeneration contractor was used for estimation purposes. The volume obtained from the first 19 filters indicated an average loss of $21.3 \%$ with a standard deviation of $4.8 \%$. The regeneration efficiency is thus $\eta_{\mathrm{r}}=0.787$.

\section{Solution of $\eta_{s}$ and $v_{h}$}

To estimate the remaining two unknowns $\mathrm{V}_{\mathrm{h}}$ and $\eta_{\mathrm{s}}$ two equations are required. The first equation is provided by a volume balance across a filter for each regeneration cycle (refer to Fig. 2):

$$
\mathrm{V}_{\mathrm{b}} \mathrm{n}_{\mathrm{b}}+\mathrm{V}_{\mathrm{r}}+\mathrm{V}_{\mathrm{h}}=\mathrm{V}_{\mathrm{s}}+\mathrm{V}_{\mathrm{r}} \eta_{\mathrm{r}}+\eta_{\mathrm{r}} \eta_{\mathrm{s}}\left(\mathrm{V}_{\mathrm{b}} \mathrm{n}_{\mathrm{b}}+\mathrm{V}_{\mathrm{h}}\right)
$$

The second equation comes from the measured volume of GAC excavated during the second sump cleaning. During this excavation, a total volume of $5.93 \mathrm{~m}^{3}$ was recovered, which reflects the cumulative GAC trapped after 1024 filter backwashes and 5 filter regeneration cycles. This provides an estimate of $1.19 \mathrm{~m}^{3} / \mathrm{cycle}$ trapped in the sump. Mathematically:

$$
\left(\mathrm{V}_{\mathrm{b}} \mathrm{n}_{\mathrm{b}}+\mathrm{V}_{\mathrm{h}}\right) \eta_{\mathrm{s}}=1.19
$$

Simultaneous solution of Eqs. (1) and (2) yields:

$$
\begin{aligned}
& \eta_{\mathrm{s}}=0.77 \\
& V_{\mathrm{h}}=1.50 \mathrm{~m}^{3} / \text { cycle }
\end{aligned}
$$

\section{Experimental verification of $\mathbf{V}_{h}$}

These results were checked by one spot measurement. A sieve was introduced in the sump overflow line, which effectively changed the trap efficiency to $100.0 \%$. The sump was then cleaned, and the GAC of one filter was removed. The sump was cleaned directly after this again, thus directly measuring $\mathrm{V}_{\mathrm{h}}$. This gave a value of $1.52 \mathrm{~m}^{3} /$ regeneration cycle, which approximates the value obtained by the model. The model as calibrated can therefore be accepted as a reliable description of the GAC flow.

\section{Residual GAC in filter after removal}

The mathematical model provides an interesting additional piece of information. The calibrated model indicates that a total of $13.9 \mathrm{~m}^{3}$ is replaced during regeneration and top-up. The filter capacity is $15.4 \mathrm{~m}^{3}$. This means that the difference of $1.5 \mathrm{~m}^{3}$ remains in the filter after removal, representing a depth of $140 \mathrm{~mm}$ of GAC, which approximates that observed in practice. This adds further credibil- ity to the mathematical model.

\section{Schematic GAC flow diagram}

The model can finally be used to calculate the average flow of GAC at each point during a typical regeneration cycle and the volumes are expressed as percentages of the total volume of GAC of a fully filled filter. This is depicted in Fig. 3.

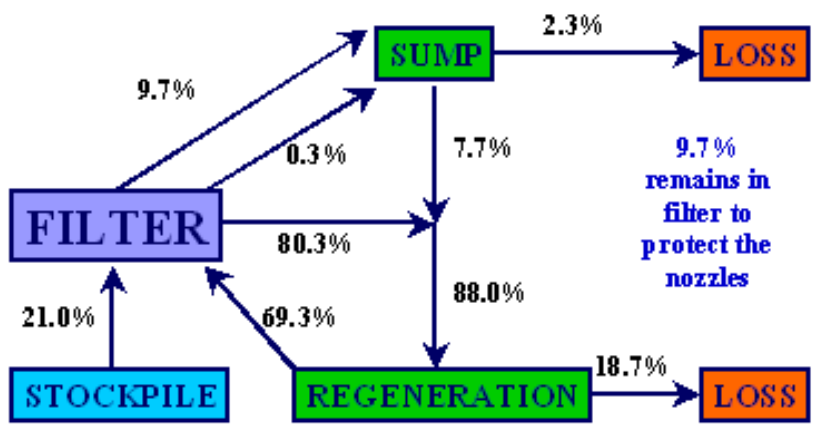

Figure 3

Summary of GAC flow during the first 23 months of operation at the Rietvlei water treatment plant

\section{Cost analyses}

With the situation modelled above, the running cost of the GAC is approximately R45 000 per regeneration cycle, to which the new top-up GAC contributes R41 500. How can the top-up then be minimised? It has already been established that these losses comprise the loss to the river and the loss during the regeneration of the GAC.

What effect will placing a sieve in front of the outlet of the sump have on the operational cost of the GAC? By changing the sump trap efficiency to 1.00 , the top-up requirement is reduced from $21.0 \%$ to $19.2 \%$ (at R16.00/kg) and the regenerated GAC returned to the filter is increased from $69.3 \%$ to $71.1 \%$ (at R2.71/ $\mathrm{kg}$ ). The total cost/regeneration cycle is thereby reduced from R45 000 to R42 000. The only other way to minimise the GAC loss is to improve the regeneration yield. If the regeneration contractor could reduce the regeneration losses to a modest $15 \%$, the top-up GAC required is reduced from $19.2 \%$ to $13.5 \%$ (at $\mathrm{R} 16.00 / \mathrm{kg}$ ), the regeneration costs increase from $71.1 \%$ to $76.8 \%$ (at R2.71/ $\mathrm{kg}$ ) and the total cost/regeneration cycle is reduced from R42 000 to R31 000 .

\section{In situ GAC behaviour}

GAC can be lost from the filters during normal operation in two ways; either by abrasion with the fines washed out during filtration and backwash, or by direct washout during filter backwash. Initially, the breakdown of the losses discussed in the previous section was unknown and it was suspected that the abrasion or washout of GAC could have significantly contributed to the total loss.

\section{GAC abrasion}

Is there measurable abrasion of the GAC in the filter due to backwashing? During operation, GAC filters operate similarly to sand filters. The backwashing, however, is done slightly differently. To curb potential abrasion of the softer GAC grains, the use of air is omitted and water alone is used. At Rietvlei, allowance was made for both water and air, but the use of air is restricted as far as 
possible and only used when necessitated by an insufficiently cleaned GAC bed. The usual procedure is a $10 \mathrm{~min}$ backwash, without air scour, approximately three times a week. To obtain a direct measure of the abrasion losses, laboratory tests were conducted whereby both the $8 \times 30$ and $12 \times 40$ GACs (the two GAC types currently used at Rietvlei) were backwashed in a filter column for $50 \mathrm{~h}$. This is equivalent to the total backwashing time a GAC filter would receive over approximately 24 months of service (10 min, three times a week). Sieve analyses were done on the GAC before and after the test and results showed no measurable effects on the GAC grain size distribution. The GAC losses due to attrition during backwash can therefore be eliminated as a measurable loss.

\section{GAC washout during backwash}

To estimate the probability of GAC washout during backwash, it is necessary to compare the expansion of the GAC bed with the available freeboard between the top of the GAC and the lip of the backwash weir. A mathematical model for bed expansion was needed for several reasons. At Rietvlei two GACs of varying size and from different manufacturers are being used, the temperature at the plant ranges between 9 and $23^{\circ} \mathrm{C}$ and there is a slight difference between the design and actual backwash rates.

\section{Calibration of a bed expansion model}

Dharmarajah (1986) developed the following predictive model using a dimensional analytical approach:

$$
\begin{aligned}
& \log B=0.56543+1.09348\left(\log \operatorname{Re}_{B}\right)+0.17979\left(\log \operatorname{Re}_{B}\right)^{2} \\
& -0.00392\left(\log \operatorname{Re}_{B}\right)^{4}-1.5(\log \psi)^{2}
\end{aligned}
$$

where:

$$
\begin{aligned}
B & =\frac{\varepsilon^{3}}{(1-\varepsilon)^{2}} \frac{\rho\left(\rho_{s}-\rho\right) g}{S_{v}{ }^{3} \mu^{2}} \\
\operatorname{Re}_{B} & =\frac{\rho V}{S_{v} \mu(1-\varepsilon)} \\
S_{v} & =\frac{6}{\psi d_{e q}} \text { or } \frac{6}{\psi d_{g}} \\
\psi & =\text { sphericity of media grains } \\
\varepsilon & =\text { predicted porosity } \\
\mu & =\text { dynamic viscosity of water } \\
\rho & =\text { density of water }\left(\mathrm{kg} / \mathrm{m}^{3}\right) \\
\rho_{\mathrm{s}} & =\text { density of media }\left(\mathrm{kg} / \mathrm{m}^{3}\right) \\
\mathrm{V} & =\text { filtration rate }(\mathrm{m} / \mathrm{s}) \\
\mathrm{d}_{\mathrm{eq}} & =\text { equivalent diameter }(\mathrm{m}) \\
\mathrm{d}_{\mathrm{g}} & =\text { geometric diameter }(\mathrm{m})
\end{aligned}
$$

To calculate the theoretical bed expansion, it is first necessary to determine the porosity of the GAC. The porosity, however, varies through the bed due to GAC size. Bed expansion tests with actual Rietvlei GAC (both $12 \times 40$ and $8 \times 30$ sizes) were conducted in the laboratory. Using the grading analyses for the GAC used in the laboratory test, the GAC bed was mathematically split into seven different layers, graded from fine to coarse. The porosity is calculated by using the Dharmarajah model. Different porosity's were chosen until Eq. (3) was satisfied. The theoretical bed expansion was then determined by using the following relationship. Here the subscript $e$ denotes the expanded value and the subscript $o$ denotes the value of the given variable for the bed before it is expanded.

$$
\frac{l_{e}}{l_{o}}=\frac{1-\varepsilon_{0}}{1-\varepsilon_{e}}
$$

where:

$l_{0}=$ media depth before the bed is expanded $(\mathrm{m})$

$l_{e}=$ media depth after the bed is expanded $(\mathrm{m})$

$\varepsilon_{0}=$ porosity before the bed is expanded

$\varepsilon_{e}=$ predicted porosity after the bed is expanded

The bed expansion tests conducted in the laboratory were used to calibrate the remaining unknown in the theoretical bed expansion model, namely the sphericity of the media. The best fits were obtained by assuming sphericity of 0.69 for the $12 \times 40$ size GAC and 0.62 for the $8 \times 30$ size GAC. The calibrated model and the original data points are shown in Fig. 4.

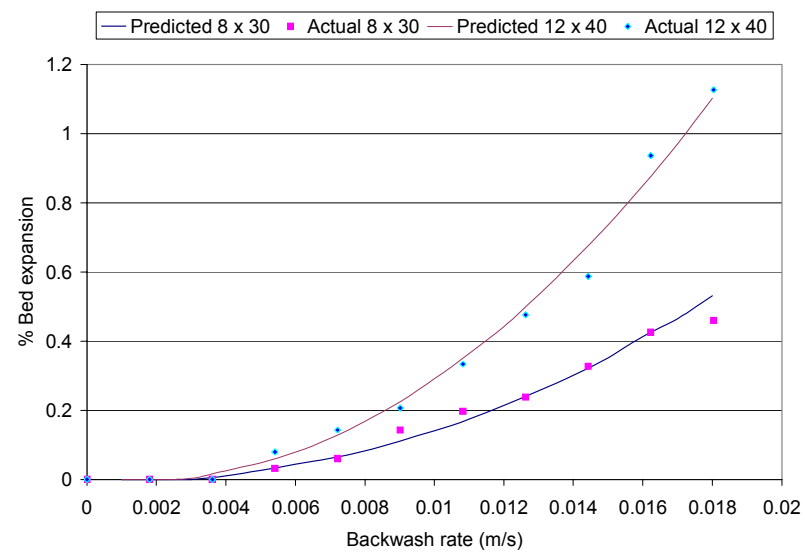

Figure 4

Theoretical and actual \% bed expansion vs. backwash rate $(12 \times 40 \& 8 \times 30)$

\section{Bed expansion and freeboard}

Could the direct washout of GAC significantly contribute to the losses? In this section, this question is explored by comparing the actual bed expansion with the available freeboard. Should the expanded layer of GAC come close to the lip of the backwash weir, the potential for GAC washout is obviously increased. The predicted expansion for the two Rietvlei GACs was calculated with the calibrated expansion model at the extreme Rietvlei temperatures of $9^{\circ} \mathrm{C}$ and $23^{\circ} \mathrm{C}$, and is shown in Fig. 5 .

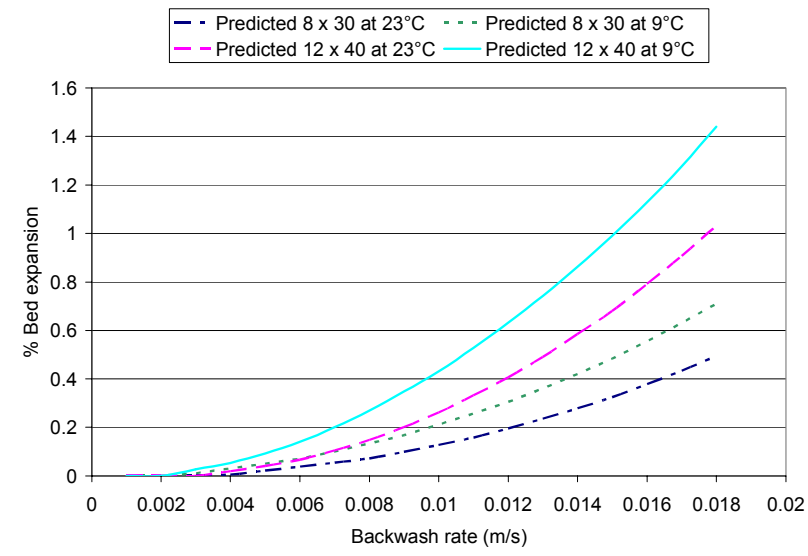

Figure 5

Actual and theoretical bed expansion vs. backwash rate for both the $12 \times 40$ and $8 \times 30$ size GACs 


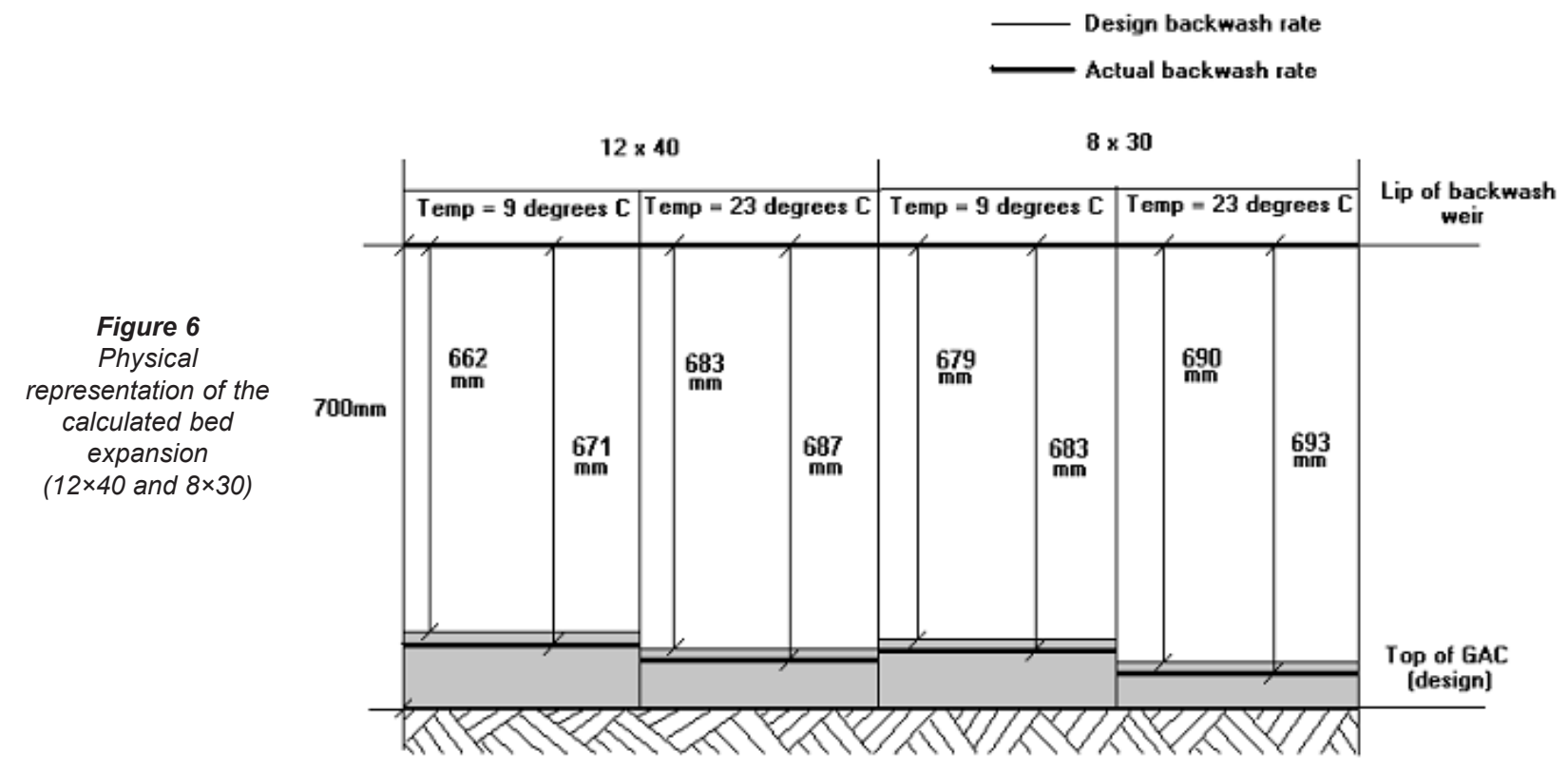

Figure 7

Physical wash-out sequence

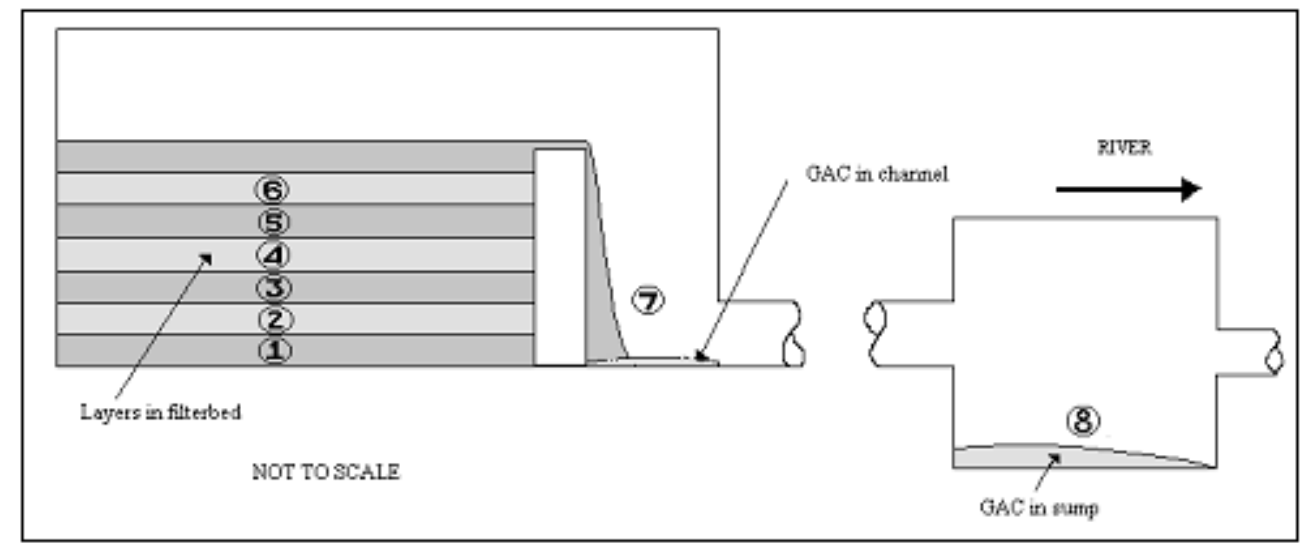

The design backwash rate is $20 \mathrm{~m} / \mathrm{h}$, and site measurements indicated an actual rise rate of $18 \mathrm{~m} / \mathrm{h}$; reasonably close to the design rate. Can an actual rise rate of $18 \mathrm{~m} / \mathrm{h}(0.0050 \mathrm{~m} / \mathrm{s})$ wash out the GAC?

The average freeboard available is $660 \mathrm{~mm}$ for the $12 \times 40$ and $680 \mathrm{~mm}$ for the $8 \times 30 \mathrm{GAC}$, indicating that the GAC should comfortably be contained within the filter bays during backwash. The design freeboard is $700 \mathrm{~mm}$.

It was, surprisingly, found that the GAC beds expand upon initial placement. Van der Aa (2001) explains this by the fact that the bed stratifies: the largest grains settle down first and the smaller grains settle down later. In the stratified bed the large grains are at the top and smaller grains at the bottom. Since the large and small grains are not mixed anymore, the porosity will be relatively high. He experienced approximately $10 \%$ expansion of the GAC bed after a stratification backwash, which would translate to $140 \mathrm{~mm}$ at Rietvlei and therefore reduce the freeboard to $560 \mathrm{~mm}$. The GAC will still be comfortably contained in the filter bay.

\section{Changes in physical properties of GAC due to backwashing}

How do the physical GAC characteristics change as the GAC moves through the operational cycle? It was already established that there are two possible routes that the GAC could follow; either through the GAC plant from the GAC filters over the weir into the channel and then washed to the sump, or from the GAC filters to the drainage tanks, transport bags, truck, and volumetric bin at the regeneration plant and then into the regeneration kiln. After that the GAC is screened, placed back into the bags, transported back to the water treatment plant on a truck and placed back in the filter with a venturi hopper. It was noticed that the properties of the GAC changed significantly during these two pathways.

\section{On-site pathway - Washout sequence}

To establish the stratification of the filter bed, core samples were taken from Filter 1. These once-off core samples were then tested for apparent density and a sieve analysis was done. In this manner, different layers in the filter bed could be analysed. Numbers 1 to 6 represent these layers in the washout sequence (Fig. 7). During a test to establish how much GAC is lost during backwashing, a sieve was placed in front of the outlet of the filter and the channel next to the weir was cleaned before and after backwashing. The GAC collected from the channel after backwashing was once again tested for apparent density and a sieve analysis was done. During the second excavation of the sump, samples were taken of the GAC washed out into it and tested as above. The changes in physical 


\begin{tabular}{|c|c|c|c|c|c|}
\hline \multicolumn{6}{|c|}{$\begin{array}{c}\text { TABLE } 1 \\
\text { The } d_{50} \text { and \% finer than } 500 \mu \mathrm{m} \text { of the sieve analyses } \\
\text { and the apparent densities and iodine numbers } \\
\text { through the washout sequence }\end{array}$} \\
\hline Position & Sample & $\begin{array}{l}d_{50}(\mu \mathrm{m}) \\
\text { number }\end{array}$ & $\begin{array}{c}\% \text { finer } \\
\text { than } \\
500 \mu \mathrm{m}\end{array}$ & $\begin{array}{c}\text { Apparent } \\
\text { density } \\
(\mathrm{g} / 100 \mathrm{~m} \ell)\end{array}$ & $\begin{array}{l}\text { lodine } \\
\text { number } \\
\text { (g/mg) }\end{array}$ \\
\hline Bed & 1 & 780 & 9.00 & 45.00 & 627 \\
\hline Bed & 2 & 970 & 5.20 & 48.20 & 650 \\
\hline Bed & 3 & 1030 & 2.70 & 48. 80 & 641 \\
\hline Bed & 4 & 1040 & 2.20 & 48. 80 & 618 \\
\hline Bed & 5 & 1060 & 2.10 & 48.80 & 638 \\
\hline Bed & 6 & 1025 & 2.11 & 48.70 & 615 \\
\hline Channel & 7 & 640 & 20.70 & 57.30 & 534 \\
\hline Sump & 8 & 750 & 10.50 & 56.10 & 388 \\
\hline
\end{tabular}

properties seemed significant, and consequently all the abovementioned samples were tested for iodine number as well. The $d_{50}$ and $\%$ finer than $500 \mu \mathrm{m}$ of the sieve analyses and the apparent densities and iodine numbers through the washout sequence are tabulated in Table 1 and the $\mathrm{d}_{50}$ and apparent densities are graphically shown in Fig. 8.

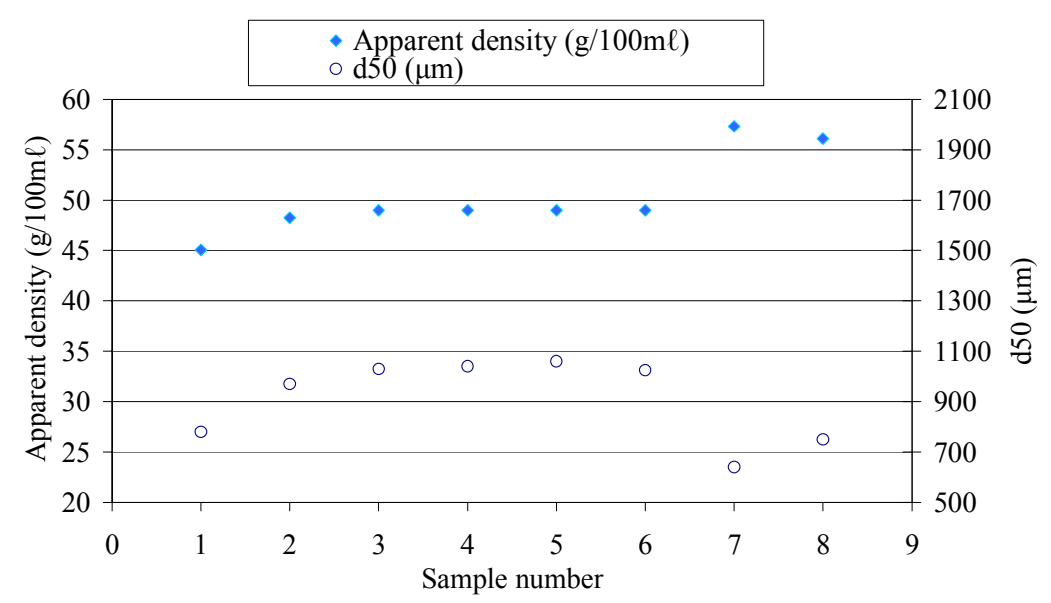

Figure 8

The $d_{50}$ and apparent densities through the washout sequence

The GAC on the bottom of the GAC bed is more abraded than the GAC higher up in the bed, having 9\% and 5\% fines in Layers 1 and 2 compared to around $2 \%$ in the rest of the bed. A stratification backwash, whereby the backwash flow is slowly decreased so that the smaller particles are the last to settle and thus settle on top, can correct this. The GAC in the channel and sump seems to be finer than the GAC in the filter, having fines of $20 \%$ and $10 \%$ respectively. This could be because of the backwash performed right after the GAC is placed back in the filter after regeneration, whereby all the fines generated by regeneration are washed out of the bed.

The apparent density of the GAC in the channel and sump also seemed significantly higher than in the filter bed. This indicates that this GAC had absorbed more organic material than the GAC in the bed. This is possibly caused by dirty backwash water washing over this GAC during every backwash. This is also reflected by the iodine numbers, which indicate that the GAC in the channel and sump has less available adsorption capacity than the GAC in the
TABLE 2

The $d_{50}$ and \% finer than $500 \mu \mathrm{m}$ of the sieve analyses and the apparent densities and iodine numbers through the regeneration cycle

\begin{tabular}{|l|c|c|c|c|c|}
\hline Position & Sample & $\mathbf{d}_{\mathbf{5 0}}(\boldsymbol{\mu m})$ & $\begin{array}{c}\% \text { finer } \\
\text { number } \\
\text { than } \\
\mathbf{5 0 0} \boldsymbol{\mu m}\end{array}$ & $\begin{array}{c}\text { Apparent } \\
\text { density } \\
(\mathbf{g} / \mathbf{1 0 0} \mathbf{m} \ell)\end{array}$ & $\begin{array}{c}\text { lodine } \\
\text { number } \\
(\mathbf{g} / \mathbf{m g})\end{array}$ \\
\hline $\begin{array}{l}\text { Filter } \\
\text { itself }\end{array}$ & 1 & 945 & 0.90 & 46.69 & 524 \\
Tank & 2 & 990 & 0.50 & 49.40 & 480 \\
Bags & 3 & 1095 & 1.60 & 49.54 & 584 \\
Before & 4 & 1087 & 0.50 & 49.54 & 533 \\
regeneration \\
Reactivated \\
\& screened
\end{tabular}

filter bed, where the adsorption capacity seems homogeneous. It seems that there is a link between apparent density and iodine number, and as apparent density can be measured within minutes after the GAC is dried, it might be a quick indicator to give an idea of the adsorption capacity left, which may be checked later by the long and tedious method of iodine number analyses.

\section{Changes in physical properties of GAC during regeneration}

To analyse the change in physical properties during the regeneration sequence, multiple samples were taken. These samples were taken in the filter, drainage tanks, bags, at the plant just before regeneration and just before the GAC is placed back in the bags after regeneration and screening. These samples were placed through a sample splitter and tested as in the previous section.

The $\mathrm{d}_{50}$ and $\%$ finer than $500 \mu \mathrm{m}$ of the sieve analyses through the regeneration sequence are tabulated in Table 2. The apparent densities and iodine numbers through the regeneration sequence are tabulated in Table 2 and the $\mathrm{d}_{50}$ and apparent densities are graphically shown in Figs. 9 and 10. The five numbers in these figures refer to the five steps in Table 2.

There seems to be no breaking up of the GAC or generation of fines during the removal and transport of the GAC during the regeneration sequence.

\section{Changes in GAC iodine number during normal operations}

How does the adsorption capacity change as the GAC moves through the operational cycle? Every GAC filter was sampled across the bed by means of extracting GAC from the middle of the bed with an injection-type sampler on 19 October 2001. The samples were mixed and its remaining adsorption capacity was measured by the laboratory staff of the Rietvlei Water Treatment Plant (the uniformity of the adsorption capacity vertically through the bed had been previously verified). The adsorption capacity (measured in $\mathrm{mg} / \mathrm{g}$ ) was then compared with the amount of days the filter had been in operation.

The iodine number and the ratio of iodine number initially and 


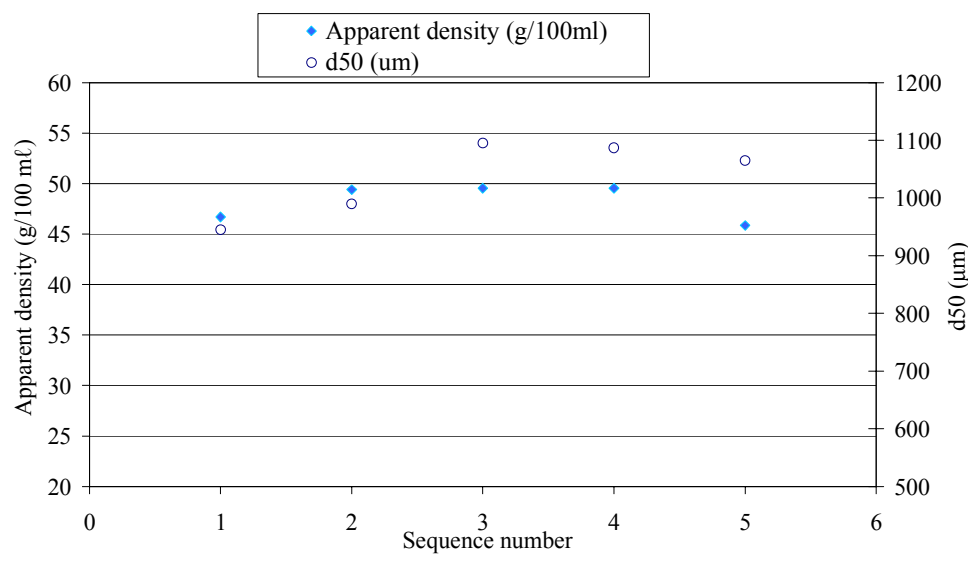

Figure 9

The $d_{50}$ and apparent densities through the regeneration sequence (fluidised bed method)

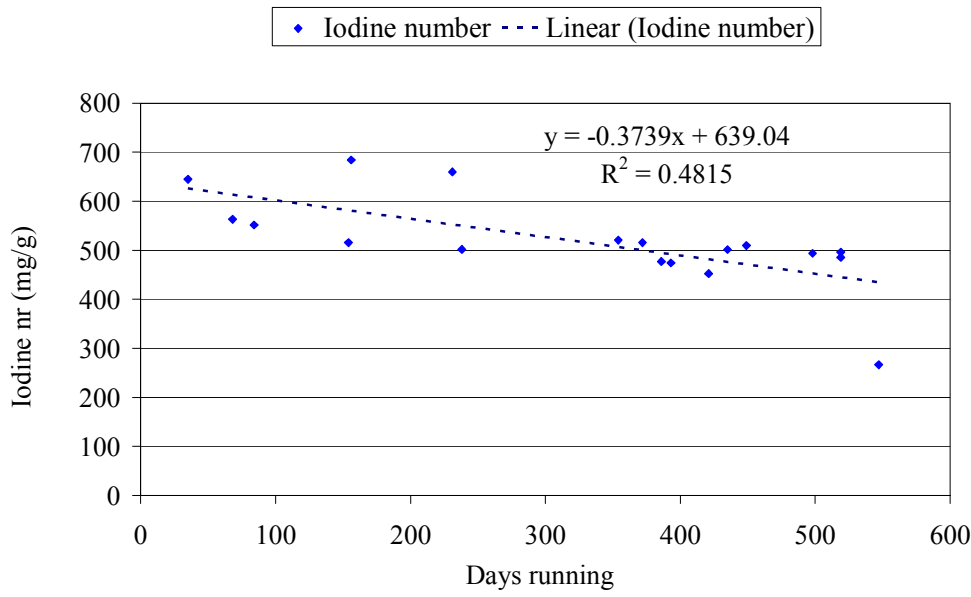

Figure 10

The iodine number as of 19/10/01 vs. the number of days the filter has been in operation model of the GAC management system was therefore constructed and calibrated.

- A small fraction of the GAC is lost from the on-site GAC recovery sump $(2.3 \%$ of the total GAC inventory per cycle). This loss can be easily eliminated by inserting a sieve in the sump outlet.

- The largest fraction of the GAC is lost during the GAC handling, transport and regeneration processes $(18.7 \%$ of the total GAC inventory as opposed to an industry standard of less than $10 \%$ ). These processes were not investigated in this study, but are currently being addressed through the specification of the regeneration contract.

- The porosity $(0.6$ for the $12 \times 40$ and 0.55 for the $8 \times 30)$, density $\left(1451 \mathrm{~kg} / \mathrm{m}^{3}\right.$ for the $12 \times 40$ and $1544 \mathrm{~kg} / \mathrm{m}^{3}$ for the $\left.8 \times 30\right)$ and sphericity $(0.69$ for the $12 \times 40$ and 0.62 for the $8 \times 30$ ) of the two GACs in use were determined, to allow the calibration of the Dharmarajah bed expansion model. This model showed that the available freeboard in the filters is adequate to comfortably contain the GAC during backwash, for both GACs used throughout the temperature range experienced at Rietvlei.

- There is neither measurable abrasion nor loss of the GAC during air scour, as measured during a $50 \mathrm{~h}$ backwash test in the laboratory.

- The physical properties of the GAC in the filter bed did not significantly differ from top to bottom, which indicates vertical movement of the GAC during backwash. The GAC washed out and collected from the backwash channel and recovery sump, however, showed substantially altered physical properties.

- The adsorption capacity of the GAC, as measured by its iodine number, linearly declines as the GAC is kept in operation. After $550 \mathrm{~d}$ of operation without regeneration (the longest time available from this study) the iodine number was still in steady decline, but at present an operational minimum iodine number of 400 is observed to ensure effective regeneration. as of 19 October 2001, vs. days that the filter had been in operation are shown in Fig. 10.

This graph shows iodine adsorption values sampled by one person, measured by one person at the Rietvlei laboratory on one day. This eliminates any possible discrepancies of different people performing the experiment under different circumstances. Figure 10 indicates that over $550 \mathrm{~d}$, the iodine adsorption had on average decreased from 630 to $430 \mathrm{mg} / \mathrm{g}$. This graph has not evened out, which indicates that there is still adsorption capacity left after $550 \mathrm{~d}$, but as previously discussed, the regeneration contractor prefers the iodine number not to drop below 400 . Thus, looking at the trend, the iodine number should reach 400 in approximately $600 \mathrm{~d}$.

\section{Summary and conclusions}

- The new GAC filtration system at the Rietvlei water treatment plant has successfully eliminated the previous water quality problems.

- The losses of GAC which have to be replenished with new, expensive GAC are higher than expected. A mathematical

\section{Acknowledgements}

This study required continuous and significant assistance from the personnel at Rietvlei water treatment plant. Carel Taljaard and his staff are therefore specially acknowledged for their assistance.

\section{References}

DE KLOE H (2000) Die Prestasie van Geaktiveerde Koolstof by Rietvlei Watersuiweringsaanleg. Pregrad Thesis for Bachelors Degree, Rand Afrikaans University.

DHARMARAJAH AH and CLEASBY JL (1986) Predicting the expansion of filter media. J. AWWA 1 (11) 66-76.

HENKET F (2001) Personal communication. Central Coast Water Authority, California USA.

KERMEEN T (2001) Personal communication. Calgon Carbon, UK

VAN DER AA (2001) Personal communication. Amsterdam Water Supply, Netherlands.

VAN STADEN AL (1996) Activated Carbon and Ozone as Supplementary Water Treatment Options at Rietvlei Dam. Master Dissertation M. Eng. (Civil)., Rand Afrikaans University.

WATER RESEARCH GROUP (2001) Sand Filtration 2001. Unpublished document: Rand Afrikaans University. 
